\title{
GÊNEROS TEXTUAIS E LETRAMENTO NA SALA DE AULA
}

\author{
Auzelene Miranda Gusmão ${ }^{1}$ \\ Edleuza Fernandes Barbosa²
}

\section{Resumo}

Este artigo trata-se de uma pesquisa sobre práticas pedagógicas de leitura, letramento e gêneros textuais. Teve como objetivo analisar as diferentes práticas de leitura, escrita e letramento, e a utilização dos diversos gêneros textuais na sala de aula, compreendendo o papel dessas práticas na formação leitora e escritora dos estudantes dos anos finais do ensino fundamental. A pesquisa apresenta abordagem qualitativa na descrição dos fenômenos encontrados na realidade. Destaca os aspectos relevantes no planejamento das propostas de atividades no ensino da construção de textos, com a finalidade de oferecer aos educandos condições de organizar coerentemente o texto conforme propósitos e situação de produção e, retrata a relevância dos gêneros textuais para a formação da competência produtora de textos.

Palavras-chave: Prática Pedagógica. Letramento. Gêneros Textuais. Produção de Texto.

\begin{abstract}
This article is a research about pedagogical practices of reading, literacy and textual genres. It aimed to analyze the different practices of reading, writing and literacy, and the use of different textual genres in the classroom, understanding the role of these practices in the reading and writing of students in the finale years of elementary school. The research presents a qualitative approach in the description of the phenomena found in reality. It highlights the relevant aspects in the planning of activity proposals in the teaching of text construction, in order to offer students conditions to coherently organize the text according to purposes and production situation, and portrays the relevance of textual genres for the formation of the production competence of texts.
\end{abstract}

Keywords: Pedagogical Practice. Literacy. Textual Genres. Text Production.

\section{Introdução}

Leitura, e produção textual, geralmente, são consideradas como atividades desenvolvidas pela instituição escolar que contribui para a formação intelectual do estudante, o exercício da cidadania e a inserção social. A escola assume o papel de promotora da competência leitora e escritora, auxiliando o indivíduo no comando

\footnotetext{
${ }^{1}$ Mestra em Ciências da Educação pela Faculdade Interamericana de Ciências Sociais - FICS; Especialista em Literatura Brasileira pela PUC-MINAS; Graduada em Letras Vernáculas pela UESB - Universidade Estadual do Sudoeste da Bahia. .Email: auzelene@yahoo.com.br

${ }^{2}$ Mestra em Ciências da Educação pela Facultad Interamericana de Ciências Sociales - FICS. Pósgraduada em Organização e Processos do Ensino Superior pela União Intermunicipal de Cursos Superiores da Bahia - UNIBA. Especialista em Psicopedagogia: institucional, clínica e hospitalar pela Faculdade Católica de Ciências Econômicas da Bahia - FACCEBA. Graduada em Pedagogia pela Universidade Católica do Salvador - UCSAL. Graduada em Letras Vernáculas pela Universidade Federal da Paraíba - UFPB. Email:dhillyfernandes@gmail.com.
} 
de habilidades de leitura e produção escrita como ferramentas imprescindíveis na vida cotidiana.

O tema Gêneros Textuais e Letramento na Sala de aula, merece ser estudado devido sua relevância para a área educacional, evidenciando a ação didática dos educadores para o desenvolvimento de capacidades cognitivas relativas ao domínio da produção textual por meio dos gêneros textuais, buscando garantir o uso da linguagem em suas múltiplas formas com autonomia de sujeitos sociais e históricos transformadores de seus ambientes e, apoderar-se da leitura e da escrita como um bem cultural no processo de compreensão do mundo.

Considerando a temática que se insere no campo da linguagem, teve-se como objetivo geral analisar as diferentes práticas de leitura e escrita e a utilização dos diversos gêneros na sala de aula, compreendendo papel dessas práticas na formação leitora e escritora dos estudantes dos anos finais do ensino fundamental. Elencando-se a partir deste, os seguintes objetivos específicos: diferenciar tipos de gêneros textuais; compreender as práticas pedagógicas de leitura, letramento e gênero no contexto escolar; perceber a estreita relação entre letramento e gêneros textuais.

Tendo em vista os objetivos dessa pesquisa, utilizou-se como metodologia a abordagem de natureza qualitativa e descritiva com a finalidade de detalhar 0 fenômeno da realidade escolar com análises, observações e reflexões acerca das práticas pedagógicas dos docentes para melhor compreensão quanto ao ensino da leitura e escrita por meio dos gêneros textuais, enfocando a pesquisa bibliográfica que consistiu na busca de materiais como bases teóricas.

Este artigo ressalta a diferença e a interdependência entre gêneros e tipos textuais, a função social e cultural da aprendizagem da escrita, a necessidade de tomar os gêneros textuais como objeto de estudo, relevante para a construção discursiva e argumentativa nas situações sócio comunicativas. Salienta a ação didática do docente com os gêneros textuais, indicando que a aprendizagem da escrita pressupõe amplo contato com a diversidade de textos, contribuindo para ampliar o nível de letramento e como suporte de qualificação da produção textual 
Após essas reflexões respaldadas em aportes teóricos que buscam realçar a qualidade da produção textual a partir da contribuição dos gêneros textuais, segue as considerações finais com sugestões de novas pesquisas equivalente ao tema, trazendo provocações ao leitor de se aventurar por outras sendas. E posteriormente, finalizando a pesquisa vêm as referências bibliográficas.

\section{Tipos e Gêneros Textuais}

Desde a década de 90, os Parâmetros Curriculares Nacionais orientam que as práticas de produção de textos orais e escritos devem ser realizadas para 0 uso da língua, tendo como base os gêneros textuais. A ênfase em sua relevância teve como efeito a revisão das propostas curriculares em todo o país e a adequação dos livros didáticos, haja vista que um dos critérios para a escolha do livro no Programa Nacional do Livro Didático (PNLD), refere-se às atividades didáticas com a diversidade dos gêneros textuais.

Atualmente temos como documento oficial que ressalta o uso dos gêneros textuais nas salas de aula a Base Nacional Curricular Comum (BNCC), que embora apresente algumas mudanças no componente da Língua Portuguesa, como a inclusão dos gêneros digitais, mantém vários pressupostos dos PCN como adoção de uma perspectiva enunciativo-discursiva da linguagem, valorizando os textos em seus contextos de produção bem como, a tomada do texto para definição de conteúdo e habilidades, partindo do gênero discursivo a que ele pertence, ligado ao uso significativo e a uma prática de linguagem.

A BNCC prevê o ensino contextualizado as práticas de linguagem, articulado ao uso social da língua, isso denota a centralidade do texto e dos gêneros textuais. Este documento traz como destaque os campos de atuação voltados para a produção e a leitura, a articulação entre as práticas de linguagem onde as habilidades de escrita aparecem integradas com práticas linguísticas de leitura e de análise linguística/ semiótica.

Estamos em convivência diária com os textos, envolvidos em situações que requer uma conduta linguística adequada, e dessas situações de linguagem resultam os gêneros e tipos textuais. Descrição, narração, dissertação, exposição e injunção são tipos textuais. O texto descritivo visa analisar uma cena, um local, 
um objeto dissertativo, objetiva informar sobre dado assunto de modo argumentativo, o narrativo conta sequência de ações reais ou imaginárias, contextualizada com o tempo, espaço, personagem e enredo, o injuntivo tem a finalidade de instruir acerca de um procedimento. Conhecer a diferença entre gêneros e tipos facilita a interpretação do texto que não está associado tão somente à construção de sentidos, mas também a aspecto imanente à estruturação textual.

Há imensa dificuldade de transmitir informações verbais, que não seja por algum gênero e é impossível se comunicar oralmente a não ser por determinado texto, sintetizando, a comunicação verbal só pode ser possível por meio dos gêneros textuais (orais e escritos), ideia defendida por Bakhtin (1997). Outros autores que concebem a língua não em suas especificidades formais, mas em seus aspectos expressivos e discursivos e a veem como atividade social, histórica e cognitiva defendem essa mesma posição de Bakhtin.

Compreende-se a suma importância da distinção entre gêneros e tipos textuais, para o trabalho com a produção de textos, torna-se fundamental que o educador consiga estabelecer a diferença entre esses termos, como conscientização das atividades relativas à linguagem escrita, Marcuschi (2005) traz alguns conceitos que permitem entender essas diferenças. Segundo o autor:

Usamos a expressão tipo textual para designar uma espécie de
construção teórica definida pela natureza lingüística de sua composição
(aspectos lexicais, sintático, tempos verbais, reações lógicas). Em geral,
os tipos textuais abrangem cerca de meia dúzia de categorias conhecidas
como: narração, argumentação, exposição, descrição, injunção. Usamos
a expressão gênero textual como uma noção propositalmente vaga para
refletir os textos materializados que encontramos em nossa vida diária e
que apresentam características sócio comunicativas definidas por
conteúdos, propriedades funcionais, estilo e composição característica
(2005, p.22).

Ainda tratando da definição dos termos acima citados, Marcuschi acrescenta que os tipos textuais são atividades cerebrais dos códigos de linguagem, constructos teóricos, constituindo em sequências linguísticas e sucessão de enunciados, englobando um conjunto limitado de categorias teóricas, enquanto que os gêneros textuais são execuções linguísticas delineadas por propriedades sócio comunicativas, incluindo o agrupamento ilimitado de designações perceptíveis, deliberada pelo canal, estilo, conteúdo, composição e função, cumprindo funções em situações comunicativas. 
Esse autor, pontua que os gêneros textuais são eventos linguísticos que se caracterizam como atividades socio-discursivas não sendo possível limitá-lo em uma lista fechada, complementa dizendo que são informações elaboradas historicamente e fornecidas sobre a cultura de quem o produziu e dos seus usuários, isto é, são artefatos culturais edificados na história humana e notavelmente reconhecido, traduzem a imagem de estruturas sociais frequentes e peculiar de cada cultura.

Alguns autores afirmam ser perigoso um conceito único e formal para os gêneros, devido não serem homogêneos, passível de interpretação "os gêneros textuais [...] são de difícil definição formal [...] quase inúmeros em diversidade de formas, obtém denominações nem sempre unívocas e, assim como surgem, podem desaparecer" (MARCUSCHI, 2005 apud DIONÍSIO, MACHADO e BEZERRA, 2003, p.20) e defendem uma vasta discussão teórica, haja vista sua diversidade na sociedade.

Demonstrando existência concreta, o gênero textual - texto em diferente formato que possuem missão comunicativa apresenta forma, estrutura linguística, assunto e se expressa em denominações diversas como: telefonema, crônica, romance, bula de remédio, cardápio, outdoor, resenha, carta comercial, biografia, entrevista, manual de instrução, conferência, bate-papo virtual, e-mail, receita culinária, etc. Sendo uma ação social, cumprindo funções em situações comunicativas, os gêneros textuais não se situam em lista completa e fechada, mas apresenta uma base interacional.

Os gêneros textuais são textos caracterizados por seu estilo, função, composição e conteúdo que apresentam aspectos sociais e comunicativos, materializados nos textos do nosso cotidiano. Por isso, o produtor de texto deve estar informado que ao escrever um texto de um determinado gênero, a tipologia também se faz presente podendo conter uma ou mais, por exemplo, conto e fábula (tipo narrativo); artigo de opinião (tipo dissertativo); entrevista e notícia (tipo dissertativo-expositivo); receita culinária e manual de instrução (tipo injuntivo). Sobre isso enfatiza Marcuschi:

É evidente que em todos esses gêneros também estão se realizando tipos textuais, podendo ocorrer que o mesmo gênero realize dois ou mais tipos. Assim, um texto é tipologicamente variado (heterogêneo). Veja-se o caso 
da carta pessoal, que pode conter uma sequência narrativa (como uma historinha), uma argumentação (argumenta em função de algo), uma descrição (descreve uma situação) e assim por diante (2003, p. 25).

Dentro dos gêneros textuais, estão os tipos textuais, geralmente os gêneros apresentam uma tipologia predominante, a saber: gêneros textuais em textos narrativos (conto, biografia, fábula, romance, lenda, novela, carta); gêneros textuais em textos descritivos (diário, anúncio de classificados, cardápio, relato de viagem); gêneros textuais em textos injuntivos (receita, manual de instrução, regras de jogo, bula); gêneros textuais em textos expositivos (verbete de dicionário e enciclopédia).

Conforme Marcuschi (2005) existe um agrupamento de gêneros textuais surgindo da conjuntura da tecnologia digital em espaços virtuais, são parcialmente variados, tais como: e-mail, chat, blog, sites eletrônicos, portais da internet, dentre outros. Os gêneros textuais podem ser modificados ao longo do tempo, devido as mutações na sociedade, é possível a criação de novos gêneros a partir de gêneros existentes, alguns se mantêm, outros desaparecem e surgem novos, eles privilegiam a funcionalidade da língua, pois, atendem as necessidades comunicativas da realidade e as demandas linguísticas.

Quando falamos em produção de texto na escola, faz-se necessário orientar os estudantes para que a construção de seus discursos tenha por base os tipos e gêneros textuais. Os tipos textuais funcionam como modos de organização, indicados por atributos linguísticos, como tempos e modos verbais, construções frasais, relações lógicas, vocabulário etc. Para melhor compreender as tipologias o autor afirma que:

Os tipos textuais constituem sequências linguísticas ou sequências de enunciados e não são textos empíricos. Teoricamente, os tipos são designados como narrativos, descritivos, argumentativos, expositivos ou injuntivos (grifos do autor). Ele enfatiza que os gêneros textuais são construídos por dois ou mais tipos, em geral. A presença de vários tipos textuais em um gênero é denominada de heterogeneidade tipológica (Id.,2003, p. 23).

A tipologia para as atividades de produção de texto na escola está correlacionada com aspectos estruturais da língua, marcado por relações lógicas, tempo verbal, características léxicas e sintáticas. São propriedades estruturais que ordena a sequência linguística e formal de um referido texto decorrente da 
intencionalidade de quem o produz: narração, descrição, dissertação, injunção e exposição. Em seus modos enunciativos, as formas de composição dos discursos nem sempre se efetivam sozinhos, geralmente adota função irregular nos diversos gêneros.

Tipos e gêneros se complementam, ambos, coexistem no texto manifestado nas funções e estruturas linguísticas. Pôr os educandos dos anos finais do ensino fundamental em contato com uma variedade de tipologia e gêneros textuais, transforma a sala de aula em oficina de textos, retomando-os e aprofundando-os, conforme $\mathrm{o}$ ano de escolarização provoca a aprendizagem da escrita de bons textos tendo em vista o interlocutor e sua finalidade.

\section{Gênero e Letramento na Sala de Aula Como Práticas Sociais}

O letramento está para além dos espaços da escola. A escrita ocupando inúmeros ambientes é uma rotina na paisagem: nos cartazes, outdoor, placas do comércio, legendas de transporte, de certa forma, o letramento recebe influência direta da escrita no panorama social surgindo a presença dos diversos gêneros textuais que permeiam o mundo contemporâneo, quer seja por meio das mídias, das tecnologias ou materiais impressos (KLEIMAN, 2005).

Torna-se imperioso que o ensino da leitura e da escrita na escola esteja em consonância com as práticas de linguagem, que os educandos usam fora da escola, eles desenvolvem muitas habilidades em ambiente externo à instituição escolar, e o currículo escolar para preencher as possíveis lacunas nos modos de como se ensina a leitura e a escrita, necessita tratar a linguagem de forma ampla em que faça sentido para os aprendizes no mundo atual.

A aquisição de conhecimentos historicamente acumulados através da escrita tem estreita relação com o letramento, que examinam as práticas sociais que abrange os usos e funções da escrita e seus efeitos sobre o indivíduo e a sociedade. A sedimentação de práticas sociais com os usos linguísticos está situada no tempo e no espaço, as quais desenvolvidas solidificam na categoria de estruturas chamadas gêneros (MARCHUSCHI, 2005).

Do ponto de vista interacional da linguagem cumpre ao ensino da leitura e da escrita, propiciar aos estudantes o acesso aos gêneros orais e escritos, dotando 
de habilidades e competências considerando as múltiplas circunstâncias que acharão na vida social. Os gêneros textuais são ferramentas de ação sobre o mundo, quando da sua aquisição os indivíduos vão compreendendo, produzindo e apreendendo o que lhe cerca, favorecendo o prazer pela leitura e escrita.

Fala e escrita embora tenham usos e objetivos múltiplos tem relação muito próxima, demonstrando muita semelhança e pouca diferença quando se considera língua e texto no conjunto das práticas sociais, de letramento ou práticas discursivas. Em uma sociedade grafocêntrica os usos sociais da escrita interagem com os diferentes gêneros orais e escritos, cabendo à escola estar atenta a essa especificidade, a fim de desempenhar sua tarefa com êxito, sendo que:

\begin{abstract}
A escrita é usada em contextos sociais básicos da vida cotidiana, em paralelo direto com a oralidade. Estes contextos são, entre outros: o trabalho, a escola, o dia-a-dia, a família, a vida burocrática, a atividade intelectual. Em cada um desses contextos, as ênfases e os objetivos do uso da escrita são variados e diversos. Inevitáveis relações entre escrita e contexto devem existir, fazendo surgir gêneros textuais e formas comunicativas, bem como terminologias e formas típicas. Seria interessante que a escola soubesse algo mais sobre essa questão para enfrentar sua tarefa com maior preparo e maleabilidade, servindo até mesmo de orientação na seleção de textos e definição de níveis de linguagem a trabalhar (Id.,2008, p. 19).
\end{abstract}

Colocar os estudantes como participantes em eventos de letramento, depende do nível de conscientização que o educador tem do valor do letramento na vida das pessoas de acordo aos contextos: casa, rua, escola, igreja, etc., que estão inseridos e da necessidade de textos (que determina o gênero textual) que precisa lançar mão para o alcance de propósitos comunicativos nas interações sociais.

Quanto mais as instituições escolares, assumem o papel de ensinar considerando as atividades humanas nos variados contextos sociais, compreendendo que o letramento está regulado por textos por meio da linguagem oral e escrita, mais the aumenta a responsabilidade de emergir os discentes na diversidade de gêneros textuais, para ampliar os níveis de letramento para a competência leitora e escritora e de participação na vida cultural.

A não distorção da natureza complexa da leitura e da escrita demanda, que a noção de letramento leve em conta os seus contextos de uso. Mesmo que a escrita não se mostre como atividade de fácil realização, uma seleção variada de 
gêneros, orientador da programação curricular, tem forte influência no modo de nos comportarmos linguisticamente, apresentando-se como referência para as nossas produções escritas. Segundo os PCN:

\begin{abstract}
Ensinar a escrever textos torna-se uma tarefa muito difícil fora do convívio com textos verdadeiros, com leitores e escritores verdadeiros e com situações de comunicação que os torne necessários [...]. Quando entram na escola, os textos que circulam socialmente cumprem um papel modelizador, servindo como fonte de referência, repertório textual, suporte da atividade intertextual. A diversidade textual que existe fora da escola pode e deve estar a serviço da expansão do conhecimento letrado do aluno (BRASIL, 1997, p.29).
\end{abstract}

O uso de gêneros textuais para fins didáticos, amplia as habilidades discursivas do sujeito usuário da língua provendo acesso a eventos de letramento, fundamental a formação pessoal, participação individual, autônoma, crítica e coletiva na sociedade. A utilização do gênero como elemento propulsor de inserção social, impulsiona a escola trazer para o seu contexto práticas extraescolar de letramento, para leitura e qualificação da produção escrita.

O processo comunicativo dos estudantes nas oportunidades de escrita, devem ser fruto da inserção dos alunos nas práticas sociais. Segundo Kleiman (2005) o ensino da língua em contexto de sentido e a reflexão sobre seus usos tem a responsabilidade de se concretizar apoiado nos gêneros textuais. A autora afirma que a realização da linguagem conforme as diretrizes e preceitos do letramento são componentes que especificam e constitui a competência comunicativa em um determinado contexto social.

Geralmente a escola, visando o desenvolvimento do escrever bem, lança mão do ensino da composição a partir de gravuras, da sequência de imagens, de redação com temas livres e/ou indicados, que se circunscreve apenas ao espaço escolar, nomeado por Schneuwly e Dolz (2004) de gêneros escolares. Essas escritas serão sempre destinadas ao educador objetivando uma avaliação do nível da escrita dos estudantes. Necessário faz ultrapassar práticas pedagógicas de produção de texto feita para a própria escola, sempre com temas definidos pelo professor que despreza a função social e interação entre os interlocutores.

Trazer para a sala de aula o mundo letrado que estamos inseridos, de vivências concretas com a diversidade textual, auxilia nas demandas de letramento. Escrever textos precisa fazer sentido para o estudante, observa-se por vezes que 
o ensino da redação, ignora os padrões básicos para a produção de textos além de evidente ausência de condições interativas e dialógicas, é preciso escrever textos para o professor e os colegas, mas também é relevante escrever para alguém fora do contexto escolar, (para um escritor, para o prefeito da cidade, etc.) observando as características do gênero e a função sócio comunicativa.

De suma importância que os textos reais circulem no interior da escola e não apenas os textos clássicos, literatura e poemas, que haja multiplicidade de momentos que conduzam os discentes a ler e a escrever, produzindo textos em diferentes gêneros textuais: propaganda, listas, receita culinária, artigo de opinião, reportagem, carta, notícia, bate-papo virtuais dentre outros, assegurando a compreensão da estrutura do gênero, características, organização linguística e reflexão sobre o funcionamento da língua.

A intervenção didática na escrita com a disposição do gênero textual em sala de aula possibilita ao estudante contextualizar sua aprendizagem, qualificar a produção de seus textos e apropriar-se do mundo letrado. Importante que haja práticas significativas e não meramente escolares, com o ensino da língua pensado sob o aspecto do letramento, mantendo o adolescente e o jovem em contato com os inúmeros textos a que eles estão expostos no dia a dia.

Na percepção de Silva (2002), o uso intensivo, múltiplo e estratégico da leitura, para a produção de bons textos e letramento em seus variados suportes e variadas funções: leitura como informação; leitura para promover a imaginação e fantasia; leitura como resolução de problemas; leitura para criticar e expor argumentos perante fatos e ideias emitidas nos textos de distintos gêneros textuais.

O letramento tem sido influenciado pelo processo de globalização e pelo surgimento da internet que força o indivíduo a interagir na era da informação, exigindo novos letramentos e estratégias de exploração do mundo virtual e adaptação do uso criativo da tecnologia visando atingir as intenções de comunicação das mensagens, onde leitura e escrita ocupe a posição de funcionalidade.

Com o surgimento de novos gêneros é fundamental que o docente ensine com os gêneros atuais usados frequentemente pelos educandos a fim de facilitar o 
seu trabalho com os gêneros na sala de aula e despertar interesse. Acreditamos ser relevante que a escola perceba que suas práticas pedagógicas com os gêneros têm de corresponder às expectativas de letramento e interesse dos educandos, sendo úteis para ação no mundo que o cerca. A adaptação do docente aos novos recursos de ensino colabora para a aprendizagem significativa e prazerosa.

O fomento de práticas linguísticas significativas na perspectiva do letramento, com destaque nos aspectos de constituição linguístico-discursiva do gênero e efetivação de sua função social, favorece a mutação cultural, a visão crítica e reflexiva e a expressão cidadã. Para tanto, faz-se necessário examinar as práticas escolares e não escolares de leitura e produção de textos, investindo nos processos de aprendizagem que permitam ao estudante apossar-se das finalidades dos gêneros escritos, construir bons argumentos, demonstrar níveis maiores de letramento no exercício da sua cidadania.

Um evento de letramento está em qualquer contexto que circunda a leitura e a escrita, o que provoca a existência de vários gêneros textuais, culturalmente determinados. Cada dia impera o compromisso do docente em elevar o grau de letramento de seus educandos de maneira constante e extensa nas atividades de leitura e escrita desenvolvidas no espaço escolar.

\section{Considerações Finais}

Nesse artigo sucedeu uma série de reflexões acerca das práticas pedagógicas de leitura, letramento e gêneros com aporte teórico, apresentando discussões referentes ao texto e sua produção, agregando os elementos indispensáveis à estrutura de um texto e a distinção entre gêneros e tipos textuais. Incluem-se as reflexões sobre letramento e uso dos gêneros textuais no contexto escolar e sua relevância para qualificar a produção escrita.

A pesquisa teve como objetivo compreender as práticas pedagógicas de leitura, letramento e gênero no contexto escolar; diferenciar tipos de gêneros textuais; perceber a estreita relação entre letramento e gêneros textuais. Enfim, analisar as diferentes práticas de leitura e escrita e a utilização dos diversos gêneros na sala de aula, compreendendo o papel dessas práticas na formação leitora e escritora dos estudantes dos anos finais do ensino fundamental. 
Os resultados da pesquisa serviram como termômetro de avaliação de como os pilares para a inserção social e para o pleno exercício da cidadania, estão sendo trabalhados na sala de aula, a leitura, o letramento e a produção textual são alicerces que estruturam o pilar da educação, para que os sujeitos se tornem cada vez mais críticos, participativos e transformadores do seu entorno social. Servem também, para suscitar reflexões sobre a prática docente, indicando temáticas para a formação continuada com vistas à educação de qualidade.

As atividades sistematizadas com a multiplicidade de gêneros em situações concretas de uso, e de textos de diversa funcionalidade, expandem as habilidades discursivas do sujeito usuário da língua, concorrem para o domínio da escrita de diferentes textos e acesso a eventos de letramento.

Enquanto profissionais da educação consideramos fundamental a pesquisa, na produção de mudanças educativas e, constante busca de construção e reconstrução do que se transmite aos educandos num processo de ação-reflexãoação, consciente do papel político de atuação social no desenvolvimento de propostas emancipatórias questionando e dialogando com a realidade, experimentando teoria e prática com ressignificação para a vida e funcionalidade no cotidiano educacional.

\section{Referências}

AKHTIN, M. Marxismo e filosofia da linguagem. 8.ed. Hucitec: São Paulo, 1997.

BRASIL. Parâmetros Curriculares Nacionais - Língua Portuguesa. Ministério da Educação. Secretaria da Educação Fundamental. Brasília, MEC/SEF, 1997.

KLEIMAN, A. Preciso "ensinar" o letramento? Não basta ensinar a escrever? Brasília: Ministério da Educação, 2005.

MARCUSCHI, L. A. Gêneros textuais: definição e funcionalidade. In: DIONÍSIO, Ângela. Paiva. (org.). Gêneros textuais \& ensino. 4ª ed. RJ: Lucerna, 2005.

MARCUSCHI, L. A. Gêneros textuais: definição e funcionalidade. In.; DIONÍSIO, Angela Paiva; MACHADO, Anna Rachel; BEZERRA, Maria Auxiliadora. (Orgs.) Gêneros textuais e ensino. 2 ed. Rio de Janeiro: Lucena, 2003.

SCHEUWLY, B; DOLZ, J. Gêneros orais e escritos na escola. Trad. E org. Roxane Rojo e Gláis Sales Cordeiro. Campinas, SP: Mercado das Letras, 2004. 
SILVA, E. T. $O$ ato de ler. Fundamentos psicológicos para uma nona pedagogia da leitura. 9 ed. São Paulo: Cortez, 2002. 